\title{
Avanços na elucidação dos mecanismos de ação de Cimicifuga racemosa (L.) Nutt. nos sintomas do climatério
}

\author{
SILVA, A.G.*; BRANDÃO, A.B.; CACCIARI, R.S.; SOARES, W.H. \\ Centro Universitário Vila Velha/UVV. Rua Comissário José Dantas de Melo, 21, Boa Vista, CEP: 29102-770, Vila \\ Velha-Brasil. *arygomes@uvv.br
}

\begin{abstract}
RESUMO: O objetivo deste trabalho foi levantar os avanços ocorridos para a compreensão da atuação terapêutica de Cimicifuga racemosa, um fitoterápico utilizado no tratamento dos sintomas do climatério em mulheres nas quais a terapia de reposição hormonal (TRH) é contra-indicada. A revisão bibliográfica possibilitou concluir que existem quatro principais hipóteses para esclarecer a base mecanística de ação: indução de apoptose por meio da ativação de caspases, inibição do ciclo celular em G1 por alteração de proteínas reguladoras, efeito central em receptor $5 \mathrm{HT}$ e ação estrogênica evidenciada pela inibição seletiva dos receptores nicotínicos da acetilcolina. Porém, é incipiente a produção científica abordando as bases moleculares que sustentem os referidos mecanismos de ação. Ainda há necessidade de elucidação quanto à possível existência de pelo menos mais um receptor estrogênico que possa ser o alvo de ligação para as substâncias ativas de $C$. racemosa, bem como avançar no conhecimento da atividade reguladora seletiva de receptores estrogênicos já evidenciada em estudos de farmacologia experimental.
\end{abstract}

Palavras-chave: menopausa, mecanismo de ação, terpenóides, compostos fenólicos, Cimicifuga racemosa

\begin{abstract}
Advances on the elucidation of mechanisms of action of Cimicifuga racemosa (L.) Nutt. in climacteric symptoms. The aim of this survey was to assemble the advances in the comprehension of the therapeutic action of Cimicifuga racemosa, a phytotherapic drug used in the treatment of climacteric symptoms in women to whom the usual hormonal replacement therapy (HRT) is counter-indicated. This literature review led to the conclusion that there are four main hypotheses to elucidate the mechanistic basis of action: apoptosis induction by means of caspase activation, cell cycle inhibition at $\mathrm{G} 1$ step through disturbance of regulatory proteins, central effect on $5 \mathrm{HT}$ receptors, and estrogenic action evidenced by selective inhibition of nicotinic acetylcholine receptors. However, scientific literature is still incipient in supporting the molecular bases for the previously proposed mechanisms of action. There is also the need to elucidate a probable new estrogen receptor that might be the target for active substances from $C$. racemosa, as well as to advance on the knowledge of the selective modulation of estrogen receptors, which has already been evidenced by experimental pharmacology.
\end{abstract}

Key words: menopause, mechanism of action, terpenoids, phenolic compounds, Cimicifuga racemosa

\section{INTRODUÇÃO}

Devido aos riscos aumentados de câncer de mama e de doenças cardiovasculares associadas à terapia de reposição hormonal - TRH (Seidlová-Wuttke et al., 2003), muitas mulheres estão buscando uma alternativa segura e também questionando a segurança da TRH (Wuttke et al., 2003b; Mahady, 2005).

Dentre as várias alternativas à TRH para aliviar os sintomas da menopausa, a literatura descreve que Cimicifuga racemosa (L.) Nutt., uma nova combinação para Actaea reacemosa L. (Ranunculaceae) teve efeitos benéficos nos fogachos em mulheres no climatério (Nappi et al., 2005; Alves et al., 2006),

Recebido para publicação em 22/11/2008 
sendo uma das plantas mais estudadas e aplicadas a estes casos (Wuttke et al., 2003a) pelo fato de representar alternativa mais segura para mulheres no climatério que apresentam contra-indicações à TRH clássica (Wuttke et al., 2003b; Radowicki et al., 2006).

No entanto, tem sido demonstrado que os extratos apresentam mais ação central do que hormonal (Borrelli et al., 2003; Viereck et al., 2005b). A eficiência tem sido por vezes questionada, demandando constantes trabalhos experimentais e de revisão sobre as evidências terapêuticas disponíveis (Borrelli \& Ernst, 2002). Há inclusive ensaios clínicos multicêntricos controlados por placebo, nos quais $C$. racemosa não apresentou nenhum efeito significativo na melhora dos sintomas climatéricos da perimenopausa (Verhoeven et al., 2005).

Mesmo diante desta controvérsia, uma monografia sobre $C$. racemosa foi incluída entre as selecionadas pela Organização Mundial de Saúde, reunindo a literatura disponível entre 1958 e 1999. Nela, as controvérsias sobre a eficácia dos extratos de $C$. racemosa são declaradas e assumidas. Mesmo assim, naquela monografia estão estabelecidos parâmetros de controle de qualidade, perfil químico, uso terapêutico, farmacologia experimental e clínica, toxicologia, dose e posologia (WHO, 2002).

O desempenho de $C$. racemosa não tem sido avaliado apenas em relação aos sinais e sintomas objetivos do período pós-menopausa. Há relatos de melhora global na qualidade de vida e em setores específicos como a saúde na menopausa, o bem estar psíquico, sexualidade e relação conjugal, diminuindo os desconfortos do período pós-menopausa em mulheres de peso corporal elevado (Molla et al., 2009).

De acordo com estudos clínicos realizados, os efeitos adversos associados ao uso de $C$. racemosa foram raros, suaves e reversíveis. As informações obtidas em registros de farmacovigilância feita por 16 laboratórios produtores de preparações à base de $C$. racemosa, a partir de relatos espontâneos de usuárias. Entre as reações adversas, estão transtornos gastrintestinais, rashes e, mais raramente, foram relatados transtornos hepáticos e circulatórios, mas as relações de causalidade entre o surgimento das reações adversas e o uso de preparações de $C$. racemosa não puderam ser estabelecidas (Huntley \& Ernst, 2003).

Os poucos relatos de hepatotoxcidade não puderam ser diretamente associados ao uso de $C$. racemosa (Mahady, 2005). Porém, avaliações feitas com linhagens de hepatócitos revelaram que ocorre morte celular nas culturas, predominantemente por apoptose, o que faz com que a toxicidade in vitro e in vivo, Este perfil de resultados foi compatível com a hepatotoxicidade idiossincrática apresentada pelos extratos de C. racemosa (Dog et al., 2003; Alves et al., 2006; Lude et al., 2007). Embora alguns casos de hepatotoxicidade tenham sido relatados, uma associação direta com a ingestão de $C$. racemosa não foi demonstrada (Mahady, 2005). Mesmo assim, atualmente, nos Estados Unidos os derivados de $C$. racemosa são recomendados a serem rotulados com avisos de alerta para a hepatotoxicidade (Mahady et al., 2008).

Apesar das recomendações de uso de $C$. racemosa e da inclusão em várias farmacopéias, na revisão bibliográfica até 2003 foi evidenciado que, em relação à atuação dos extratos de $C$. racemosa no tratamento dos desconfortos do climatério, ainda não eram conclusivas as informações a respeito do mecanismo de ação (Dog et al., 2003).

Em função disto, este trabalho tem por objetivo realizar uma revisão de literatura sobre os extratos de $C$. racemosa em busca de subsídios que permitam elaborar proposta em relação aos mecanismos de ação que sustentam a atuação terapêutica.

\section{Perfil fitoquímico de Cimicifuga racemosa}

As partes da planta utilizadas, como matériaprima para a obtenção dos extratos farmacêuticos, correspondem aos órgãos subterrâneos - rizoma e raízes (Burdette et al., 2002; Chen et.al., 2002). O processamento do material botânico para extração compreende a pulverização das partes subterrâneas da planta para extração com metanol, etanol e isopropanol. A padronização é aplicada ao extrato etanólico e ao isopropanólico na proporção de correspondência em 40 a 60\% em relação à matériaprima (WHO, 2002).

Os ácidos cimicifúgicos (Figura 1) correspondem a uma série de ésteres dos ácidos hidroxicinâmicos com os ácidos fukíico e piscídico que foram isolados do extrato hidro-etanólico (1:1), dos rizomas de $C$. racemosa. Entre eles, estão os ácidos 2- fukinólico, cimicifúgico $A$, cimicifúgico $B$, cimicifúgico $\mathrm{E}$ e cimicifúgico $\mathrm{F}$. Além deles, também foram encontrados na forma livre os ácidos cafeicos, ferúlico e isoferúlico (Kruse et al., 1999).

Os principais constituintes característicos de C. racemosa são representados pelos triterpenos cicloanostâmicos, denominados cimiracemosídeos (Shao et al., 2000) e triterpenos derivados do cicloartanol (Chen et al., 2002), livres ou na forma de heterosídeos. Dentre as classes de substâncias biologicamente ativas encontradas em $C$. racemosa, estão seus respectivos heterosídeos (Figura 2): acteol, acetilacteol, 26-desoxiacteol, cimigenol e derivados, acteína, 26-desoxiacteína, cimicifugosídeo (WHO, 2002), cimiracemosídeo, desoxiacteína, oacetil-shengmanol, actaepóxido, o-acetilcimigenol e 27-desoxiacteína (Tsukamoto et al., 2005). 
A<smiles>O=C(O)/C=C/c1ccc(O)c(O)c1</smiles>

B<smiles>COc1cc(/C=C/C(=O)O)ccc1O</smiles>

C acido ferúlico<smiles>COc1ccc(/C=C/C(=O)O)cc1O</smiles>

D<smiles>CC(=O)OC(=O)[C@](O)(Cc1ccc(O)c(O)c1)C(O)C(=O)O</smiles>

$E$<smiles>O=C([O-])O[Ge](Cl)(Cl)OC(=O)[C@@](O)(Cc1ccc(O)cc1)C(O)C(=O)O</smiles>

F<smiles>O=C(/C=C/c1ccc(O)c(O)c1)OC(C(=O)O)[C@@](O)(Cc1ccc(O)c(O)c1)C(=O)O</smiles>

G<smiles>COc1cc(/C=C/C(=O)OC(C(=O)O)[C@](O)(Cc2ccc(O)c(O)c2)C(=O)O)ccc1O</smiles>

Ácido cimicifúgico $\mathrm{A}$

$\mathrm{H}$<smiles>COc1ccc(/C=C/C(=O)OC(C(=O)O)[C@@](O)(Cc2ccc(O)c(O)c2)C(=O)O)cc1O</smiles>

Ácido cimicifúgico B

I<smiles>COc1cc(/C=C/C(=O)OC(C(=O)O)[C@](O)(Cc2ccc(O)cc2)C(=O)O)ccc1O</smiles>

Ácido cimicifúgico $\mathrm{E}$

$J$<smiles>COc1ccc(/C=C/C(=O)OC(C(=O)O)[C@](O)(Cc2ccc(O)cc2)C(=O)O)cc1O</smiles>

Ácido cimicifúgico $\mathrm{F}$

FIGURA 1. Cimicifuga racemosa. Ácidos hidroxicinâmicos (A, B, C) e ácidos cimicifúgicos (D - J)

Também foram encontrados, fenilpropanóides, como a cimifugina, uma cromona, e a isoflavona formononetina (Figura 3). Apesar de presente na planta, a formononetina foi detectada apenas nos extratos isopropanólicos, estando ausente do extrato etanólico (Struck et al., 1997) e metanólico (Kennelly et al., 2002). Também foram descritos entre os componentes, os ácidos aromáticos e derivados, na forma de ésteres de ácidos cinâmicos (Hostanska et al., 2004b; He et al., 2006).

$\mathrm{Na}$ busca de marcadores fitoquímicos que permitissem diferenciar quimicamente o material vegetal proveniente de $C$. racemosa, daqueles oriundos de outras espécies próximas do mesmo gênero, foi determinado por cromatografia líquida de alta eficiência acoplada à espectrometria de massasCLAE-MS, que o heterosídeo triterpênico cimigenol3-O-arabinosídeo, a cimifugina e o heterosídeo cimifugina-3-O-glucosídeo revelaram-se adequados à identificação química de $C$. racemosa, funcionando, portanto, como marcadores específicos que permitem identificação química em relação a outras espécies de Cimicifuga (He et al., 2006).

O extrato metanólico do rizoma de $C$. racemosa, que funciona como insumo para a produção de fitomedicamentos, quando caracterizado através 


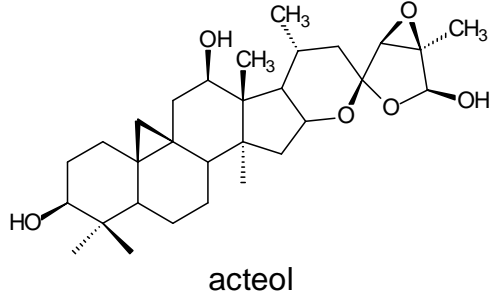<smiles>CC1CC2OC3(OC2C(C)(C)O)C1[C@H](O)[C@@H]1C2CCC4C(C)(C)C(O)CCC45CC25CCC13C</smiles>

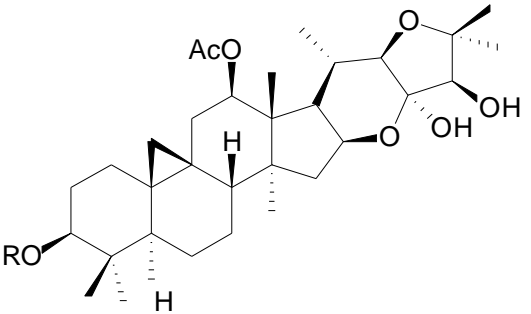

cimiracemosídeo

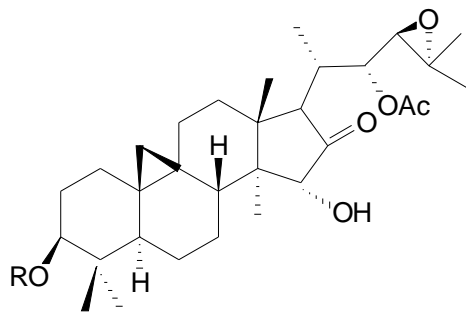
acetil-shengmanol

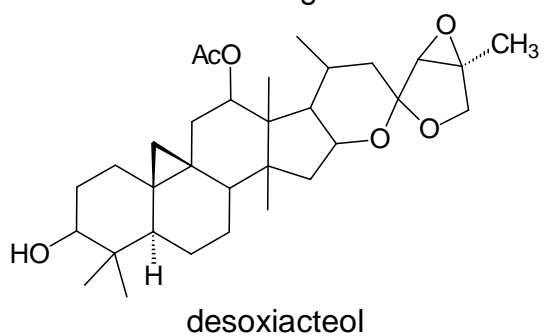

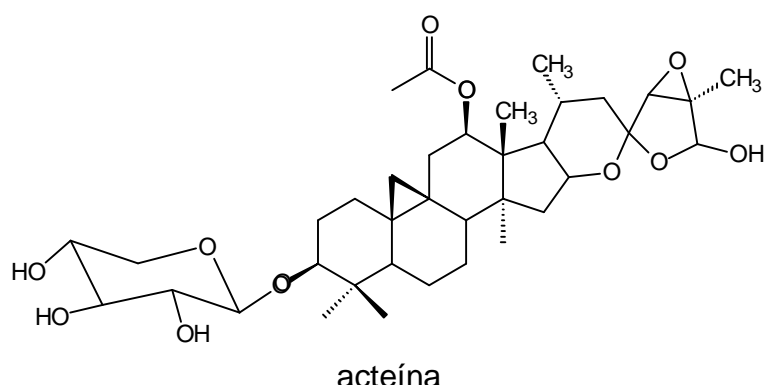

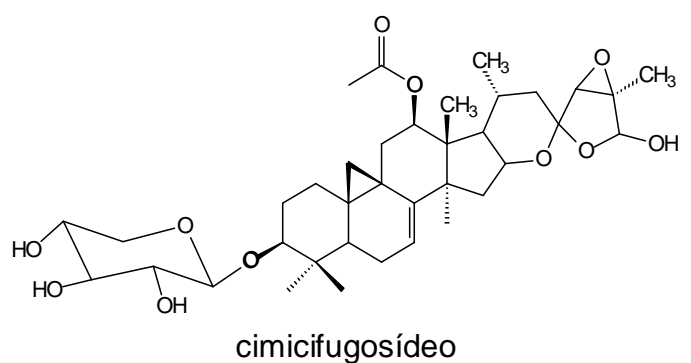

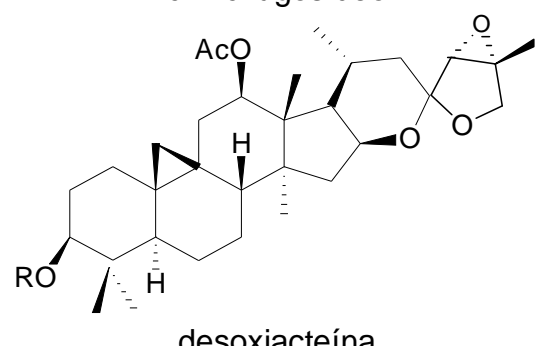

desoxiacteína

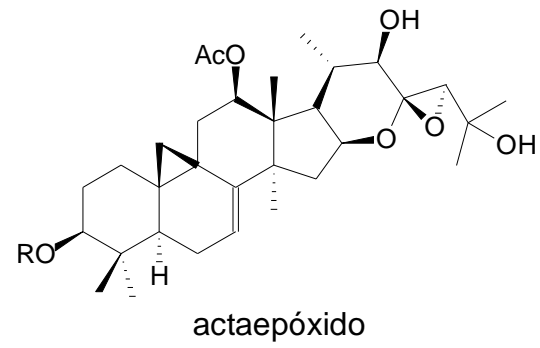

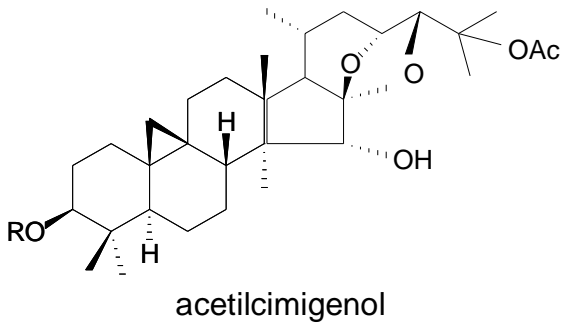

FIGURA 2. Cimicifuga racemosa. Triterpenos seus heterosídeos.

a análise realizada por cromatografia de fase gasosa acoplada à espectrometria de massas (CG-MS), foi demonstrado que o ácido 9-10-metilenohexadecanóico foi o marcador específico para a identificação desta espécie. Entre os critérios complementares de avaliação de controle de qualidade, para padronização da $C$. racemosa foram incluídas as análises quantitativas da formononetina, por cromatografia de camada delgada (TLC), do éster metílico do ácido isoferúlico (GC-MS), e dos heterosídeos triterpênicos totais, determinados em teores de acteína, que foram transformados em complexos coloridos e medidos por espectrofotometro (Panossian et al., 2004).

Recentemente, foi atribuída à existência da substância, a N(w)metilserotonina (Figura 3), a potente atividade sobre receptores $5 \mathrm{HT}_{7}$ (Powell et al., 2008; Godecke et al., 2009). 
A<smiles>COc1ccc(-c2coc3cc(O)ccc3c2=O)cc1</smiles>

formononetina
B<smiles>COc1c2c(cc3oc(CO)cc(=O)c13)OC(C(C)(C)O)C2</smiles>

C<smiles>CNCCc1c[nH]c2ccc(O)cc12</smiles>

FIGURA 3. Cimicifuga racemosa. Compostos fenólicos: isoflavona (A) e cromona (B). Compostos alcaloídicos (C).

\section{Atividades farmacológicas evidenciadas}

C. racemosa é planta nativa do leste da América do Norte, onde é conhecida como black cohosh (WHO, 2002), sendo denominada no Brasil como cimicífuga (Brasil, 2008). Os extratos dessa planta foram usados historicamente como antiinflamatórios, antipiréticos e analgésicos dentre outras indicações, como no tratamento das cólicas menstruais e nos sintomas da menopausa (Bolle et al., 2007). Recentemente passou a ser utilizado em todo mundo, mas principalmente nos Estados Unidos e na Europa, por mulheres para aliviar os sintomas do climatério (Vermes et al., 2005).

Embora a TRH fosse usada por muito tempo para as indicações anteriormente citadas, atualmente é contra indicada para a maioria das mulheres com histórico de câncer de mama, devido à possibilidade do estrogênio estimular o crescimento de células cancerígenas (Rock \& Demichelle, 2003).

Diante deste quadro, muitas mulheres na pós-menopausa estão buscando tratamento alternativo, como $C$. racemosa, que possui indicativos de efeito inibitório na proliferação do câncer de mama humano (Hostanska et al., 2005) e no câncer de próstata (Jarry et al., 2005). A dose atual do extrato de $C$. racemosa recomendada é de $40-80 \mathrm{mg} \mathrm{dia}^{-1}$ (Mahady, 2005).

Os sintomas do climatério correspondem à a principal indicação terapêutica dos extratos de $C$. racemosa (Wuttke et al., 2003a), principalmente em mulheres com contra-indicação relativa para a $\mathrm{TRH}$ (Wuttke et al., 2002). Entre as principais ações estão a diminuição intensa dos fogachos (Mahady et al., 2002; Vermes et al., 2005); a diminuição da ansiedade, depressão, cefaléia, distúrbios do sono e vertigens (Borreli \& Ernst, 2002; Vermes et al., 2005) e a melhora acentuada da atrofia vaginal (Wuttke et al., 2003b).

Embora haja consenso na literatura sobre a indicação terapêutica dos extratos de C. racemosa no tratamento dos desconfortos do climatério, o mecanismo de ação que leva a esta indicação ainda é controverso (WHO, 2002). Há ocasiões em que um efeito estrogênico dose-dependente é apresentado (WHO, 2002; Beck et al., 2003). Em outras, é demonstrado que o extrato de C. racemosa apresenta ação central em vez de ação hormonal e o mecanismo de ação ainda não é conhecido (Borrelli et al., 2003). Mas há também evidências de efeitos antiestrogênicos dos extratos etanólico e isopropanólico de C. racemosa, que antagonizou a estimulação induzida pelo estradiol, tanto pela inibição da proliferação celular em linhagem de células MCF-7 de câncer de mama, como pela supressão da expressão gênica para este tipo de tumor (Zierau et al., 2002). Ao contrário do que se esperava, os extratos de $C$. racemosa têm exibido discreta atividade antiestrogênica (Kretzschmar et al., 2005)

A avaliação comparativa demonstrou que 0 extrato hidro-isopropanólico de $C$. racemosa administrado a grupos de pacientes com queixas do climatério foi equivalente ao estradiol quando administrado a grupo em paralelo que recebeu o estradiol transdérmico, quando a dose do extrato foi de $40 \mathrm{mg} \mathrm{dia}^{-1}$. Neste ensaio clínico aleatorizado foram acompanhadas 64 mulheres pós-menopáusicas antes e três meses após o início do tratamento, registrando-se o número diário de fogachos, sintomas vasomotores e urogenitais, sintomas psíquicos como depressão e ansiedade, níveis plasmáticos de gonadotrofinas, lipídios e lipoproteínas, enzimas de avaliação da função hepática, e medidas da espessura do endométrio, produzindo resultados comparados pelo teste t pareado (Nappi et al., 2005).

$\mathrm{O}$ extrato em etanol absoluto mostrou-se superior ao placebo durante o tratamento de pacientes com distúrbios menstruais, em avaliação clínica multicêntrica controlada por placebo (Frei-Kleiner et al., 2005).

A associação de tamoxifeno com o extrato de $C$. racemosa BNO 1055 por um período de doze meses levou à diminuição satisfatória dos fogachos provenientes do climatério (Hernandez-Muñoz \& Pluchino, 2003). Este fato, aliado aos poucos efeitos colaterais que o extrato de C. racemosa apresenta, sugere que estes compostos apresentam atividade moduladora seletiva de receptor de estrogênio, o que diminui a possibilidade de estímulo a tumores mamários e uterinos (Wuttke et al., 2003b; Alves et al., 2006). 
Apesar disto, estudos recentes demonstraram que não houve diferença significativa entre o tratamento com o extrato de $C$. racemosa e o placebo em mulheres no climatério sobreviventes de câncer de mama. Foram semelhantes os resultados entre o grupo tratado com $C$. racemosa e o com placebo, sendo que somente o suor diminuiu significativamente em pacientes que receberam $C$. racemosa (Rock \& Demichele, 2003).

As isoflavonas genisteína e daidzeína, presentes na soja e no trevo vermelho respectivamente, possuem expressivo efeito osteoprotetor em mulheres pós-menopausa. Tal efeito não foi observado para a formononetina, uma isoflavona presente em $C$. racemosa. (Setchell \& Olsen, 2003).

Em controvérsia, há registro na literatura sobre as propriedades osteoprotetoras positivas para os extratos da $C$. racemosa. A melhora na qualidade do osso, a diminuição da perda óssea e o aumento na resistência mecânica à fratura foram observados após o uso do extrato isopropanólico de $C$. racemosa (Nisslein \& Freudenstein, 2003; Viereck et al., 2005a).

Os extratos etanólicos e isopropanólicos BNO 1055 de C. racemosa foram equipotentes a estrógenos e a fármacos dopaminérgicos (Mahady, 2005). Este extrato não induziu a proliferação do endométrio e produziu melhoras nas queixas dos sintomas do climatério em estudo feito com 400 mulheres na pós-menopausa, o que faz dele recurso seguro no tratamento dos desconfortos do climatério (Raus et al., 2006). É recomendada a dose de 40 a $80 \mathrm{mg} \mathrm{dia}^{-1}$ do extrato de C. racemosa. Para isto, foram necessárias de 4 a 12 semanas de tratamento para que aparecessem os benefícios terapêuticos. A utilização de $C$. racemosa é contra-indicada na gravidez e durante a lactação e em lactentes e crianças até 12 anos, devido ao efeito estrogênico relatado (Mahady et al., 2002; WHO, 2002).

Os extratos etanólicos e isopropanólicos BNO 1055 são equipotentes a estrógenos e a fármacos dopaminérgicos. Sendo que $30 \mathrm{mg} \mathrm{Kg}^{-1} \mathrm{de}$ imipramina correspondem, em potência, a dose entre 50 e $100 \mathrm{mg} \mathrm{Kg}^{-1}$ deste extrato (Winterhoff et al., 2003).

\section{Interações medicamentosas}

Alguns alimentos e ervas medicinais aumentam a disponibilidade oral dos substratos de CYP3A4, a família de citocromo P450 mais abundante no fígado e epitélio intestinal humano. $O$ extrato de $C$. racemosa exibiu inibição potente de CYP3A4, sendo que a fração polar do extrato, onde se encontram os heterosídeos triterpênicos, mostrou inibição significativa (Tsukamoto et al., 2005). Houve também inibição significativa da CYP2D6, mas a magnitude do efeito (cerca de 7\%), não parece apresentar relevância clínica (Gurley et al., 2005).

Em suma, a administração concomitante de
C. racemosa com qualquer tipo de medicamento deve ser evitada devido à possibilidade de aumentar a concentração biodisponível dos fármacos no sangue. Isso ocorre pela supressão de CYP3A4, que causa uma regulação para baixo desta enzima (Tsukamoto et al., 2005).

\section{Possíveis mecanismos de ação}

\section{Ação estrogênica}

De C. racemosa é obtido o extrato BNO 1055 , do qual $40 \mathrm{mg}$ equivalem, em efeito, a 0,6 mg do conjugado hormonal estrogênico, apresentando efeitos centrais sobre o hipotálamo e efeitos hormonais sobre a composição do epitélio vaginal e na descalcificação óssea (Wuttke et al., 2003b). Esse extrato exerce também efeitos estrogênicos sobre o tecido adiposo, mas não sobre o útero, parecendo possuir na composição, moduladores seletivos para receptores estrogênicos (Seidlová-Wuttke et al., 2003; Wuttke et al., 2003b).

Em ensaio clínico controlado por placebo, realizado com 62 mulheres pós-menopáusicas, tanto o extrato de $C$. racemosa, como o conjugado estrogênico trouxeram benefícios para o metabolismo ósseo. O extrato de $C$. racemosa estimulou a atividade dos osteoblastos, enquanto o conjugado estrogênico apresentou inibição da atividade dos osteoclastos. Enquanto o conjugado estrogênico apresentou fortes efeitos sobre a mucosa vaginal, o extrato de $C$. racemosa apresentou fraca atividade estrogênica (Wuttke et al., 2006).

A atividade protetora contra osteoporose do extrato de $C$. racemosa pode ser conseqüência de um heterosídeo triperpenoídico. Os osteoclastos ocupam lugar central na patogênese da osteoporose, uma vez que são eles os responsáveis pela reabsorção óssea, induzida por citocinas que estão normalmente aumentadas nestas condições. Como o 25-acetilcimigenol-xilopiranosideo, presente na planta, bloqueia potencialmente in vitro a osteoclastogênese, ele pode estar envolvido na diminuição a reabsorção óssea (Qiu et al., 2007).

Há indícios de que a proteção contra a descalcificação óssea não seja apenas conseqüência de eventual inibição da osteoclastogênese. Para verificar isto foram feitos ensaios avaliando o efeito in vitro do extrato de $C$. racemosa em linhagens de próosteoblastos de camundongos. Apesar do extrato de C. racemosa estimular a diferenciação dos próosteoblastos em osteoblastos, que participam da recomposição óssea (Viereck et al., 2005a), que também inibiu a proliferação de osteoblastos em doses de $1000 \mathrm{ng} \mathrm{mL}^{-1}$. Houve aumento significativo na nodulação óssea em doses de $500 \mathrm{ng} \mathrm{mL}^{-1}$. Reações em Cadeia de Polimerase - PCR evidenciaram aumento da expressão gênica de 
proteínas que participam do processo de mineralização óssea. Este aumento foi inibido pela co-administração de antagonistas seletivos de receptores de estrogênio. Este fato evidencia mecanismo estrogênico para atuação do extrato de C. racemosa na proteção contra perdas ósseas ocorrentes após a menopausa (Chan et al., 2008).

Entretanto, até 2003, estudos realizados sobre $C$. racemosa constataram existir na composição alguma substância ainda desconhecida que deve se ligar a algum receptor estrogênico não descrito no endométrio, e que algum composto dopaminérgico desconhecido deve contribuir para o perfil farmacológico do extrato (Jarry et al., 2003).

Esta idéia ainda persiste em parte. A fração lipofílica do extrato hidro-alcoólico de C. racemosa induziu atividade inibitória dose-dependente sobre a resposta in vitro à ocitocina, prostaglandina $F(2-\alpha)$ e à bradicinina no útero em ratas de 28 dias, numa razão de potência de quase 1:30 em relação ao 17- $\beta$ estradiol. Isto justifica a atividade de $C$. racemosa na diminuição do estresse menstrual e das cólicas durante o período. Porém, permanece não identificado o receptor estrogênico ao qual os componentes da fração lipofílica se ligam (Bolle et al., 2007).

A atuação dos componentes fitoquímicos de C. racemosa como moduladores seletivos de receptor de estrogênio (Wuttke et al., 2003b; Alves et al., 2006) parece se consolidar entre os possíveis mecanismos de ação. Apesar do extrato de $C$. racemosa não ter aumentado significativamente a expressão do receptor á-estrogênico, em avaliação do endométrio em úteros de ratas Wistar, ele foi capaz de diminuir significativamente a expressão da proteína Ki67, inibindo significativamente a proliferação endometrial, quando comparado com o placebo (Alves et al., 2008).

A inibição de receptores nicotínicos de acetilcolina também consiste numa das atividades dos estrógenos em animais. O cimicifugosídeo, um dos constituintes ativos de $C$. racemosa, inibe a secreção de catecolaminas pelas células cromafins da adrenal bovina, bloqueando o receptor nicotínico de acetilcolina. Inibe também o influxo de cálcio induzido pelo iodeto de 1,1-dimetil-4-fenilperperazina (DMPP), que é agonista de receptores nicotínicos das células cromafins da adrenal bovina (Woo et al., 2004).

Por outro lado, o cimicifugosídeo não altera o influxo de cálcio quando este é provocado por níveis altos de potássio. O aumento do sódio pelo DMPP também foi inibido pelo cimicifugosídeo. Estes resultados sugerem que o cimicifugosídeo inibe seletivamente a resposta dos receptores nicotínicos das células cromafins da adrenal bovina, causando inibição da secreção de catecolaminas. Sendo assim, ainda é prematura a associação entre a inibição dos receptores inotrópicos da acetilcolina pelo cimicifugosídeo e o alívio dos sintomas do climatério, como os fogachos (Woo et al., 2004).

De tudo o que pode ser investigado em relação à atividade estrogênica do extrato de $C$. racemosa, algumas questões metodológicas podem ter contribuído para as controvérsias que ainda persistem na literatura. Entre os possíveis problemas metodológicos estão a elevada taxa de resultados falso-positivos nos ensaios de inibição competitiva; a detecção de atividade estrogênicas, apesar da capacidade de ligação a receptores estrogênicos; a atividade moduladora seletiva de receptores estrogênicos, ou mesmo a atividade aditiva ou sinérgica àqueles receptores (Overk et al., 2008).

\section{celular \\ Ação não estrogênica sobre a proliferação}

A indução de apoptose pode ser atribuída a uma ou duas frações principais do extrato hidroisopropanólico da $C$. racemosa, a dos heterosídeos triterpênicos e dos ésteres do ácido cinâmico que contribuíram significativamente para o efeito apoptótico. Os ésteres do ácido cinâmico foram mais potentes tanto como inibidores da proliferação celular como na indução de apoptose. A indução de apoptose por frações contendo heterosídeos triterpênicos e de ésteres do ácido cinâmico ocorre em concentrações bem abaixo daquelas requeridas para detectar inibição significativa na proliferação celular (Hostanska et al., 2004b).

O extrato de C. racemosa inibiu a proliferação de células carcinogênicas humanas de tumores de mama, levando à morte tanto células estrogênioreceptor-positivas como estrogênio-receptor-negativas, pela indução de apoptose por meio da ativação de caspases e não exerceu nenhuma atividade proliferativa (Hostanska et al., 2004a). O mesmo mecanismo foi evidenciado em relação a linhagens de células humanas de câncer de próstata, tem ocorrido tanto a morte de células andrógeno-receptorpositivas como andrógeno-receptor-negativas (Hostanska et al., 2005).

As caspases são enzimas que têm papel central na apoptose celular, possuindo ação associada à clivagem de proteínas essenciais à célula. A deficiência de caspase 3 é responsável pela insensibilidade relativa de células cancerígenas MCF7 a muitos agentes quimioterápicos (Hostanska et al., 2004b).

Dados recentes sugerem que o controle do ciclo celular, particularmente em G1 e as transições em G2 são fundamentais para assegurar a divisão exata da célula. Pesquisa realizada em células de câncer de mama MCF-7 mostrou que a acteína, a 26-desoxiacteína e o cimiracemosídeo suprimem a fase G1 do ciclo celular, induzindo alterações nas proteínas regulatórias ciclina D1, cdk4 e p21, 
impedindo a proliferação celular (Hostanska et al., 2004b).

\section{Efeito central em receptores 5-HT}

Constituintes do extrato de $C$. racemosa comportam-se como ligante competidor do receptor de serotonina, ligando-se a receptores $5-\mathrm{HT}_{(1 \mathrm{~A})}$, 5$\mathrm{HT}_{(1 \mathrm{D})}$ e $5-\mathrm{HT}_{(7)}$, atuando como mistura de ligantes competitivos para o receptores $5 \mathrm{HT}_{(7)}$, típicos do hipotálamo, local onde acontecem as reações de fogachos. Aelevação do AMP cíclico (AMPc), mediada pelo extrato de $C$. racemosa, pode ser revertida na presença do antagonista metiotepina, indicando a mediação por receptores, e também, que a diminuição dos fogachos pode se processar muito mais por ação central do que estrogênica. No entanto, há necessitando de maiores investigações a respeito (Burdette et al., 2003).

Como receptores e carreadores serotoninérgicos estão envolvidos na termorregulação, os constituintes do extrato de $C$. racemosa foram testados para a atividade serotoninérgica, utilizando testes in vitro, de ligação a receptores $5-\mathrm{HT}_{(7)}$, de indução de síntese do AMP cíclico - cAMP, e de inibição seletiva da recaptação de serotonina.

Esta atividade sertoninérgica foi inicialmente atribuída aos ácidos cimicifúgicos, mas com a descoberta de alcalóides fortemente básicos do tipo cimipronidina, foi levantada a hipótese de que a $\mathrm{N}(\omega)$ metilserotonina seria a responsável pela ação serotoninérgica (Powell et al., 2008).

Os extratos brutos apresentaram ligação aos receptores $5-\mathrm{HT}_{(7)}$, e indução de síntese de cAMP. Os triterpenóides e os ácidos fenólicos não apresentaram tal atividade, enquanto a $\mathrm{N}(\omega)$ metilserotonina foi capaz de se ligar a receptores 5$\mathrm{HT}_{(7)}\left(\mathrm{Cl}_{50}=23 \mathrm{pM}\right)$, indução do $\operatorname{cAMP}\left(\mathrm{CE}_{50}=22\right.$ $\mathrm{nM})$, e bloqueio da recaptação de serotonina $\left(\mathrm{Cl}_{50}=\right.$ 490 nM) (Powell et al., 2008). Estes dados sugerem que a $\mathrm{N}(\mathrm{w})$ metilserotonina seja a responsável pela atividade serotoninérgica de $C$. racemosa (Godecke et al., 2009).

\section{CONCLUSÃO}

Em virtude da revisão bibliográfica que foi realizada, concluímos que as bases moleculares do mecanismo de ação da $C$. racemosa podem ser vistas hoje por um horizonte mais amplo, tendo sido desenvolvidas quatro hipóteses de trabalho que norteiam as principais vias mecanísticas possíveis: indução de apoptose por meio da ativação de caspases, inibição da proliferação celular pela interrupção do ciclo celular em G1, através de alteração das proteínas reguladoras, efeito central em receptor $5 \mathrm{HT}$ na diminuição dos fogachos, e a ação estrogênica na proteção á perda de densidade óssea e ressecamento da mucosa vaginal.

Porém, é incipiente a produção científica abordando as bases moleculares que sustentem os mecanismos de ação para os marcadores do extrato de $C$. racemosa. Ainda há necessidade de elucidação quanto à possível existência de pelo menos mais um receptor estrogênico que possa ser o alvo de ligação para as substâncias ativas de C. racemosa, bem como avançar no conhecimento da atividade reguladora seletiva de receptores estrogênicos já evidenciada em estudos de farmacologia experimental.

\section{REFERÊNCIA}

ALVES, D.L. et al. Avaliação crítica das ações da Cimicífuga racemosa no climatério. Femina, v.34, n.4, p.269-74, 2006.

ALVES, D.L. et al. Effects of Trifolium pratense and Cimicifuga racemosa on the endometrium of wistar rats. Maturitas, v.61, n.4, p.364-70, 2008.

BECK, V. et al. Comparison of hormonal activity (estrogen, androgen and progestin) of standardized plant extracts for large scale use in hormone replacement therapy. Journal of Steroid Biochemistry and Molecular Biology, v.84, n.2-3, p.259-68, 2003.

BOLLE, P. et al. Estrogen-like effect of a Cimicifuga racemosa extract sub-fraction as assessed by in vivo, ex vivo and in vitro assays. Journal of Steroid Biochemistry and Molecular Biology, v.107, n.3-5, p.2629, 2007.

BORRELLI, F. et al. Pharmacological effects of Cimicifuga racemosa. Life Sciences, v.73, n.10, p.121529, 2003.

BORRELLI, F.; ERNST, E. Cimicifuga racemosa: a systematic review of its clinical efficacy. European Journal Clinical Pharmacology, v.58, n.4, p.235-41, 2002.

BRASIL. Agência Nacional de Vigilância Sanitária. Instrução normativa no $\mathbf{8 9}$, de 11 de dezembro de 2008. Determina a publicação da "Lista de medicamentos fitoterápicos de registro simplificado". Disponível em: $<$ http://www.anvisa. gov.br/edicamentos/fitoterapicos/ index.htm>. Acesso em: 29 abr. 2009.

BURDETTE, J.E. et al. Black cohosh (Cimicifuga racemosa L.) protects against menadione-induced DNA damage through scavenging of reactive oxygen species: bioassay-directed isolation and characterization of active principles. Journal of Agriculture and Food Chemistry, v.50, n.24, p.7022-8, 2002.

BURDETTE, J.E. et al. Black cohosh acts as a mixed competitive ligand and partial agonist of the serotonin receptor. Journal of Agriculture and Food Chemistry, v.51, n.19, p.5661-70, 2003.

CHAN, B.Y. et al. Ethanolic extract of Actaea racemosa (black cohosh) potentiates bone nodule formation in MC3T3-E1 preosteoblast cells. Bone, v.43, n.3, p.56773, 2008.

CHEN, S.N. et al. Cimiracemosides I-P, new 9,19cyclolanostane triterpene glycosides from Cimicifuga racemosa. Journal of Natural Products, v.65, n.10, p.1391-7, 2002. 
DOG, T.L. et al. Critical evaluation of the safety of Cimicifuga racemosa in menopause symptom relief. Menopause, v.10, n.4, p.299-313, 2003.

FREI-KLEINER, S. et al. Cimicifuga racemosa dried ethanolic extract in menopausal disorders: a doubleblind placebo-controlled clinical trial. Maturitas, v.51, n.4, p.397-404, 2005.

GODECKE, T. et al. Phytochemistry of cimicifugic acids and associated bases in Cimicifuga racemosa root extracts. Phytochemical Analysis, v.20, n.2, p.120-33, 2009.

GURLEY, B.J. et al. In vivo effects of goldenseal, kava kava, black cohosh, and valerian on human cytochrome P450 1A2, 2D6, 2E1, and 3A4/5 phenotypes. Clinical Pharmacology and Therapeutics, v.77, n.5, p.415-26, 2005.

HE, K. et al. Cimicifuga species identification by high performance liquid chromatography-photodiode array/ mass spectrometric/evaporative light scattering detection for quality control of black cohosh products. Journal of Chromatography A, v.1112, n.1-2, p.241-54, 2006.

HERNANDEZ-MUÑOZ, G.; PLUCHINO, S. Cimicifuga racemosa for the treatment of hot flushes in women surviving breast cancer. Maturitas, v.44, sup.1, p.S59-65, 2003. HOSTANSKA, K. et al. Cimicifuga racemosa extract inhibits proliferation of estrogen receptor-positive and negative human breast carcinoma cell lines by induction of apoptosis. Breast Cancer Research and Treatment, v.84, n.2, p.151-60, 2004a.

HOSTANSKA, K. et al. Evaluation of cell death caused by triterpene glycosides and phenolic substances from Cimicifuga racemosa extract in human MCF-7 cancer cells. Biological and Pharmaceutical Bulletin, v.27, n.12, p.1970-5, 2004b.

HOSTANSKA, K. et al. Apoptosis of human prostate androgen-dependent and -independent carcinoma cells induced by an isopropanolic extract of black cohosh involves degradation of cytokeratin (CK) 18. Anticancer Research, v.25, n.1A, p.139-47, 2005.

HUNTLEY, A.; ERNST, E. A systematic review of the safety of black cohosh. Menopause, v.10, n.1, p.58-64, 2003.

JARRY, H. et al. In vitro effects of the Cimicifuga racemosa extract BNO 1055. Maturitas, v.44, suppl.1, p.S31-8, 2003. JARRY, H. et al. Cimicifuga racemosa extract BNO 1055 inhibits proliferation of the human prostate cancer cell line LNCaP. Phytomedicine, v.12, n.3, p.178-82, 2005.

KENNELLY, E.J. et al. Analysis of thirteen populations of black cohosh for formononetin. Phytomedicine, v.9, n.5, p.461-7, 2002.

KRETZSCHMAR, G. et al. No estrogen-like effects of an isopropanolic extract of Rhizoma Cimicifugae racemosae on uterus and vena cava of rats after 17 day treatment. Journal of Steroid Biochemistry and Molecular Biology, v.97, n.3, p.271-7, 2005.

KRUSE, S.O. et al. Fukiic and piscidic acid esters from the rhizome of Cimicifuga racemosa and the in vitro estrogenic activity of fukinolic acid. Planta Medica, v.65, n.8, p.763-4, 1999.

LUDE, S. et al. Hepatic effects of Cimicifuga racemosa extract in vivo and in vitro. Cellular and Molecular Life Sciences, v.64, n.21, 2848-57, 2007.

MAHADY, G.B. Black cohosh (Actaea/Cimicifuga racemosa): review of the clinical data for safety and efficacy in menopausal symptoms. Treatments in
Endocrinology, v.4, n.3, p.177-84, 2005.

MAHADY, G.B. et al. Black cohosh: an alternative therapy for menopause. Nutrition and Clinical Care, v.5, n.6, p.283-9, 2002.

MAHADY, G.B. et al. United States Pharmacopeia review of the black cohosh case reports of hepatotoxicity. Menopause, v.15, n.4, p.628-38, 2008.

MOLLA, M.D. et al. Cimicifuga racemosa treatment and health related quality of life in post-menopausal Spanish women. Gynecology and Endocrinology, v.25, n.1, p.216, 2009.

NAPPI, R.E. et al. Efficacy of Cimicifuga racemosa on climacteric complaints: a randomized study versus lowdose transdermal estradiol. Gynecological Endocrinology, v.20, n.1, p.30-5, 2005.

NISSLEIN, T.; FREUDENSTEIN, J. Effects of an isopropanolic extract of Cimicifuga racemosa on urinary crosslinks and other parameters of bone quality in an ovariectomized rat model of osteoporosis. Journal of Bone and Mineral Metabolism, v.21, n.6, p.370-6, 2003. OVERK, C.R. et al. High-content screening and mechanism-based evaluation of estrogenic botanical extracts. Combined Chemistry High Throughput Screening, v.11, n.4, p.283-93, 2008.

PANOSSIAN, A. et al. Methods of phytochemical standardisation of rhizoma Cimicifugae racemosae. Phytochemical Analysis, v.15, n.2, p.100-8, 2004.

POWELL, S.L. et al. In vitro serotonergic activity of black cohosh and identification of $\mathrm{N}$ (omega)-methylserotonin as a potential active constituent. Journal of Agriculture and Food Chemistry, v.56, n.24, p.11718-26, 2008.

QIU, S.X. et al. A triterpene glycoside from black cohosh that inhibits osteoclastogenesis by modulating RANKL and TNFalpha signaling pathways. Chemical Biology, v.14, n.7, p.860-9, 2007.

RADOWICKI, S. et al. Skutecznosc i bezpieczenstwo stosowania suchego wyciagu z klacza Cimicifuga racemosa w leczeniu objawów zespolu menopauzalnego. Ginekologia Polska, v.77, n.9, p.678-83, 2006.

RAUS, K. et al. First-time proof of endometrial safety of the special black cohosh extract (Actaea or Cimicifuga racemosa extract) CR BNO 1055. Menopause, v.13, n.4, p.678-91, 2006.

ROCK, E.; DEMICHELE, A. Nutritional approaches to late toxicities of adjuvant chemotherapy in breast cancer survivors. American Society for Nutritional Sciences, p.3785-93, 2003.

SEIDLOVÁ-WUTTKE, D. et al. Pharmacology of Cimicifuga racemosa extract BNO 1055 in rats: bone, fat and uterus. Maturitas, v.44, n.1, p.39-50, 2003.

SETCHELL, K.; OLSEN, E.L. Dietary phytoestrogens and their effect on bone: evidence from in vitro and in vivo, human observational, and dietary intervention studies. American Journal of Clinical Nutrition, v.78, sup., p.S593-609, 2003.

$\mathrm{SHAO}$, Y. et al. Triterpene glycosides from Cimicifuga racemosa. Journal of Natural Products, v.63, n.7, p.905$10,2000$.

STRUCK, D. et al. Flavones in extracts of Cimicifuga racemosa. Planta Medica, v.63, n.3, p.289-90, 1997.

TSUKAMOTO, S. et al. Isolation of CYP3A4 inhibitors from the black cohosh (Cimicifuga racemosa). EvidenceBased Complementary and Alternative Medicine, v.2, 
n.2, p.223-6, 2005.

VERHOEVEN, M.O. Effect of a combination of isoflavones and Actaea racemosa Linnaeus on climacteric symptoms in healthy symptomatic perimenopausal women: a 12-week randomized, placebo-controlled, double-blind study. Menopause, v.12, n.4, p.412-20, 2005. VERMES, G. et al. The effects of remifemin on subjective symptoms of menopause. Advances in Therapy, v.22, n.2, p.148-54, 2005.

VIERECK, V. et al. Isopropanolic extract of black cohosh stimulates osteoprotegerin production by human osteoblasts. Journal of Bone Mineralization Research, v.20, n.11, p.2036-43, 2005a.

VIERECK, V. et al. Black cohosh: just another phytoestrogen? Trends in Endocrinology and Metabolism, v.16, n.5, p.214-21, 2005b.

World Health Organization-WHO. Rhizoma cimicifugae racemosae. In: WHO monographs on selected medicinal plants. Geneve: WHO, 2002. v.2, p.55-65.

WINTERHOFF, $\mathrm{H}$. et al. Cimicifuga extract BNO 1055: reduction of hot flushes and hints on antidepressant activity. Maturitas, v.44, suppl.1, p.51-8, 2003.

WOO, K.C. et al. Phytoestrogen cimicifugoside-mediated inhibition of catecholamine secretion by blocking nicotinic acetylcholine receptor in bovine adrenal chromaffin cells. Journal of Pharmacology and Experimental Therapeutics, v.309, n.2, p.641-9, 2004.

WUTTKE, W. et al. Phytoestrogens for hormone replacement therapy? Journal of Steroid Biochemistry and Molecular Biology, v.83, n.1-5, p.133-47, 2002.

WUTTKE, W. et al. Phytoestrogens: endocrine disrupters or replacement for hormone replacement therapy? Maturitas, v.44, n.1, p.S9-20, 2003a.

WUTTKE, W. et al. The Cimicifuga preparation BNO 1055 vs. conjugated estrogens in a double-blind placebocontrolled study: effects on menopause symptoms and bone markers. Maturitas, v.44, suppl.1, p.S67-77, 2003b. WUTTKE, W. et al. Effects of black cohosh (Cimicifuga racemosa) on bone turnover, vaginal mucosa, and various blood parameters in postmenopausal women: a double-blind, placebo-controlled, and conjugated estrogens-controlled study. Menopause, v.13, n.2, p.18596, 2006.

ZIERAU, O. et al. Antiestrogenic activities of Cimicifuga racemosa extracts. Journal of Steroid Biochemistry and Molecular Biology, v.80, n.1, p.125-30, 2002. 